\title{
Preparing Industry for Additive Manufacturing and Its Applications: Summary \& Recommendations from a National Science Foundation Workshop
}

\author{
Timothy W. Simpson ${ }^{1 *}$ \\ Mechanical \& Industrial Engineering \\ Pennsylvania State University \\ State College, PA, USA
}

\author{
Christopher B. Williams ${ }^{2}$ \\ Mechanical Engineering \\ Virginia Tech \\ Blacksburg, VA, USA
}

\author{
Michael Hripko ${ }^{3}$ \\ Youngstown State University \\ Youngstown, $\mathrm{OH}$, USA
}

\section{ABSTRACT}

Accompanying the increasing advances and interest in Additive Manufacturing (AM) technologies is an increasing demand for an industrial workforce that is knowledgeable about the technologies and how to apply them to solve real-world problems. As a step towards addressing this knowledge gap, a workshop was held at the National Science Foundation (NSF) to discuss the educational needs to prepare industry for AM and its use in different fields. The workshop participants - 66 representatives from academia, industry, and government - identified several key educational themes: (1) AM processes and process/material relationships, (2) engineering fundamentals with an emphasis on materials science and manufacturing, (3) professional skills for problem solving and critical thinking, (4) design practices and tools that leverage the design freedom enabled by AM, and (5) cross-functional teaming and ideation techniques to nurture creativity. The paper summarizes the industry speakers and presentations from the workshop, along with several new educational partnerships identified by small working groups. Based on the presentations and partnerships, the following recommendations are offered to advance the AM workforce. First, ensure that all AM curricula provide students with an understanding of (i) $\mathrm{AM}$ and traditional manufacturing processes to enable them to effectively select the appropriate process for product realization; (ii) the relationships between AM processes and material properties; and (iii) "Design for AM", including computational tools for AM design as well as

\footnotetext{
${ }^{1 *}$ Professor and Corresponding Author, tws8@psu.edu

${ }^{2}$ Associate Professor, cbwill@vt.edu

${ }^{3}$ Former Deputy Director, America Makes, Workforce \& Education Outreach, mahripko@ysu.edu
} 
frameworks for process selection, costing, and solution generation that take advantage of AM capabilities. Second, establish a national network for AM education that, by leveraging existing "distributed" educational models and NSF's ATE Programs, provides open source resources as well as packaged activities, courses, and curricula for all educational levels (K-Gray). Third, support K-12 educational programs in STEAM (STEM plus the arts) and across all formal and informal learning environments in order to learn the unique capabilities of AM while engaging students in hands-on, tactile, and visual learning activities to prepare them for jobs in industry while learning how to think differently when designing for AM. Fourth, provide support for collaborative and community-oriented maker spaces that promote awareness of AM among the public and provide AM training programs for incumbent workers in industry and students seeking alternative pathways to gain AM knowledge and experience. Recommendations for scaling and coordination across local, regional, and national levels are also discussed to create synergies among the proposed activities and existing efforts.

\section{INTRODUCTION}

\subsection{Motivation for the Workshop}

Additive Manufacturing (AM) is leading a rebirth of interest and activity in advanced manufacturing in the United States. The hype and promise for AM has been driven as much by technological advances (e.g., the ability to manufacture fully-dense metal parts for production) as by the commodification of existing AM technologies (e.g., desktop-scale 3D printers). Many of these $\mathrm{AM}$ and 3D printing (3DP) advances lie on opposite ends of the Technology Readiness Scale, yet together they are generating unprecedented interest in this decades-old technology.

While enthusiasm for AM has grown substantially recently, widespread use and industrial adoption of AM for production of end-use products has been tempered. In addition to the 
technical challenges (e.g., lack of metrology and production standards, limited working materials, uncertainties in part qualification), one acknowledged barrier to AM adoption is the workforce's unfamiliarity with the technologies' capabilities, their working materials, and techniques for designing products to take full advantage of the potential offered by AM.

The need to educate future design and manufacturing engineers was a core focus of the 2009 Roadmap for Additive Manufacturing [1-3], as unfamiliarity with AM technologies is a significant hurdle for industrial adoption. The roadmap urges the development of university courses and "programs for educating the general population to enhance the interest in AM applications and generate some societal 'pull' for the technologies" [1]. Fundamentally, to realize the full potential of AM, engineers must (i) fully understand AM technologies and AM materials, (ii) know how to design products for fabrication via AM, (iii) be able to synthesize AM's economic and environmental impacts on a manufacturing value chain, and (iv) understand how to effectively communicate and ultimately qualify AM parts.

While some AM courses at the undergraduate and graduate levels do exist (see, e.g., $[4,5]$ ), their limited quantity does not match the recent interest in, and national importance of, AM technology. Recent textbooks on AM (e.g., $[6,7])$ will satisfy some of this interest and provide overviews of AM technology, but providing scalable hands-on experiences to train thousands of students and incumbent workers is a challenge. For instance, the Center for Innovative Materials Processing through Direct Digital Deposition at Penn State offers 4-day industry practicum sessions that combine lectures with hands-on activities in their AM facilities. They have trained more than 240 industry practitioners in the past three years, but participation is limited to 40 people per class due to space constraints and safety concerns. Many AM facilities face similar 
challenges and must balance the time spent training against time spent doing research and work for their industry partners.

Numerous workshops have been held in the past year to address AM's critical research and technical challenges [8-10]. Specifically, these workshops have focused on (i) assisting newcomers in becoming familiar with the technology, (ii) presenting research opportunities to those communities that have yet to interface with AM, and/or (iii) presenting updates on the dynamically changing technologies.

To date, none of these workshops have convened experts from industry, academia, non-profit organizations, and government agencies to discuss the specific educational needs and opportunities - and corresponding partnerships — for the AM workforce. To address this gap, we organized a Steering Committee (see Acknowledgements) with support from NSF and America Makes to hold a 1.5-day workshop on AM education and training at NSF in Arlington, VA. The goals and objectives for the workshop are discussed next.

\subsection{Workshop Goals \& Objectives}

While there is clearly a need to educate a workforce that is capable of intelligently employing AM technologies, the means for appropriately addressing this gap are not well defined. Advancing the understanding, utilization, and adoption of AM and will require an interdisciplinary workforce that has the knowledgebase for synthesizing new materials, integrating advanced process controls, establishing quality control standards, and formulating new design and communication methodologies. The knowledge, skills, and abilities necessary to work effectively with AM technologies are not well understood — and are changing quicklygiven how rapidly the field is evolving. What should we be teaching students about AM? What do graduate students need to know versus undergraduates? What technical training should be 
offered at community colleges? What types of AM-related skills are needed in industry? How best to capture and integrate the interdisciplinary knowledge needed to take full advantage of all of AM's capabilities? There are unlimited opportunities given the promise of AM, but what are the real needs, and subsequently, what are the knowledge, skills, and abilities that we should be teaching our students to work in this rapidly changing environment?

Addressing these issues was the primary goal for the workshop. Specifically, the goal of the workshop was to bring together participants from academia, industry, and government agencies to actively engage in discussions related to, and develop efforts for, enhancing the AM workforce through new and novel educational and training partnerships. Workshop objectives for achieving this goal included:

- Providing a foundation for preparing the workforce for AM;

- Identifying new ways to work effectively across a wide spectrum of educational needs-graduate, undergraduate, community colleges, technician training, industry practitioners, and 'makers'; and

- Identifying synergies between existing AM educational efforts and funding to realize new education and training partnerships.

An overview of the workshop is presented in Section 2. The results from the workshop's breakout session are presented in Section 3. We close the paper with a summary of the key workshop outcomes and recommendations for enhancing the AM workforce. A detailed description of the workshop and its outcomes can be found in the workshop report [11].

\section{METHODOLOGY: WORKSHOP OVERVIEW}

Faced with the broad overall workshop goal to identify efforts for enhancing the AM workforce through novel educational partnerships, the authors chose to approach the 
organization of the workshop in the framework of the engineering design process (see Figure 1). Thus, the first workshop activity was to define the problem. In the context of AM education, the task was to discuss what should be taught to the future AM workforce at all educational levels (e.g., first to senior year in both university and community colleges). Moving into the conceptual design phase, the workshop engaged its participants in conceiving of means by which AM principles should be taught. The workshop concluded by engaging the participants in the embodiment and detail design phases of the design process, i.e., identifying funding opportunities and partnerships to realize new AM workforce development efforts.

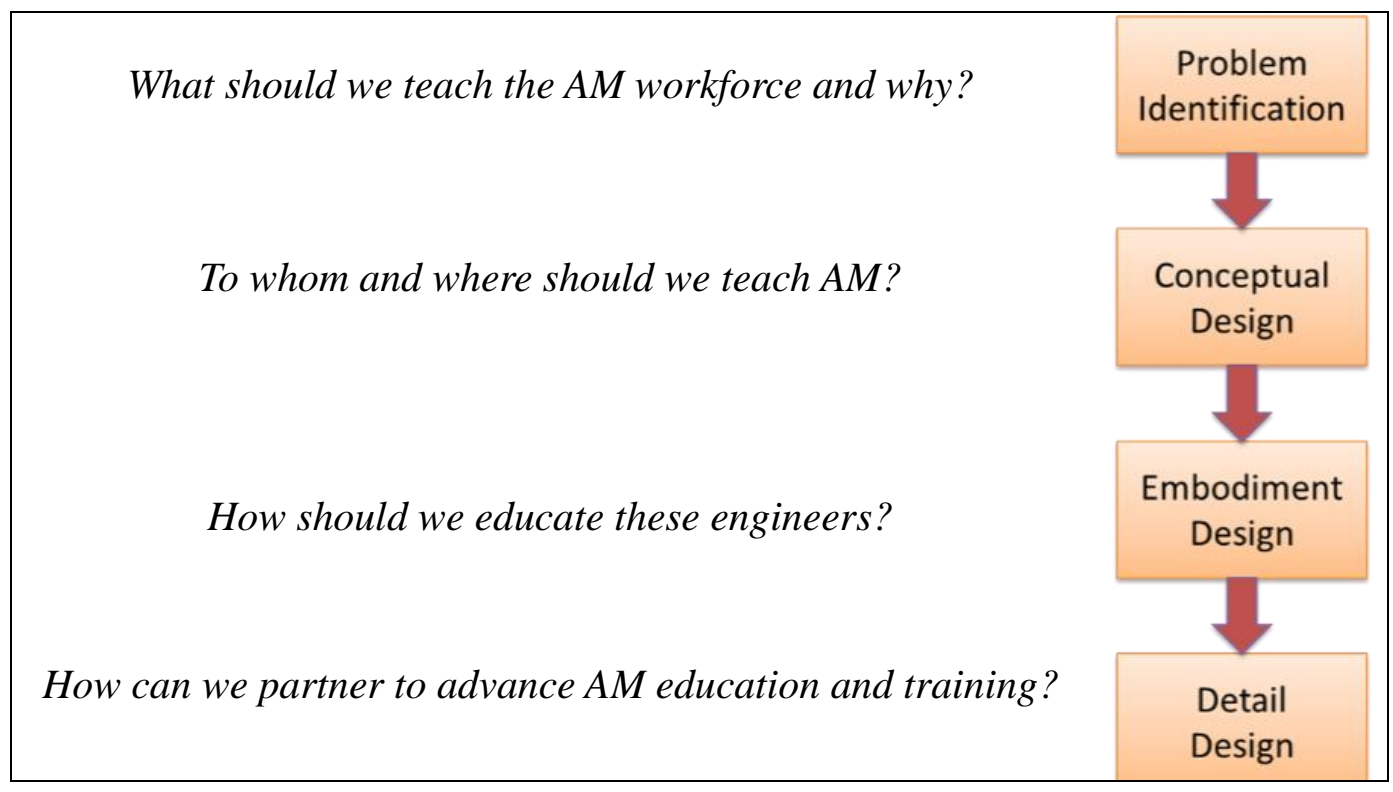

Figure 1. Workshop Structure as a Process of Design

\subsection{Participants and Speakers}

Working with the Steering Committee, workshop participants were solicited from a variety of sources and communities involved with AM education, research, and training. We compiled a list of approximately 150 possible participants for the workshop. An invitation to register for the workshop was emailed twice to these candidates. In total, 66 participants attended the workshop. 
The participants spanned a variety of industries (19), universities and colleges (27), community colleges (9), and government and non-profit agencies (11).

\subsection{Workshop Structure}

Given the overall approach presented in Figure 1, the workshop agenda was structured around three working group sessions that divided participants into small groups and tasked them with answering key questions for enhancing the AM workforce. Each working group session was preceded by a series of invited speakers who provided brief "lightning" talks to provide context to the discussions. A total of 25 speakers gave presentations at the workshop. All of the speakers' slides can be found on the workshop website [12].

- Working Group \#1: What should we teach to the AM workforce and why? Before tackling this question, invited speakers from industry discussed their AM workforce needs. Their presentations were framed around the question, "What are the characteristics of an ideal AM engineer?" to identify the "customer needs" for the future AM workforce. The working groups then elaborated on the knowledge and skills for the AM workforce and discussed concepts that an AM educational program should cover.

- Working Group \#2: To whom, where, and how should we teach AM? The second day of the workshop began with a series of invited speakers from universities and community colleges who shared their "best AM educational practices". This gave the participants insight into new ways to teach and use AM before they broke into their working groups to generate ideas for novel AM educational approaches.

- Working Group \#3: How should we partner for AM education and training? To help the group identify means of implementing broad reaching educational programs, several speakers from government agencies and related organizations discussed national efforts and 
funding opportunities for AM education and training. Working groups were then formed, and participants were challenged with generating concepts for a novel, scalable AM workforce education and training programs.

\section{RESULTS: WORKSHOP OUTCOMES}

The workshop began with a keynote speech from Mr. Ed Morris, Director of America Makes/NAMII. He summarized the national interest and investment in AM, and highlighted its ability to effectively democratize manufacturing and to enable a new generation of entrepreneurs. Given this opportunity, Mr. Morris stressed the importance of educating the future workforce at all levels: public and K-12 (general awareness), workforce (non-degree through graduate), and advanced AM research and education, especially since many other nations (e.g., Singapore, China, Taiwan, South Korea [13]) are investing significantly in these same areas. After his opening comments, the workshop proceeded as outlined in Section 2.2.

\subsection{What should we teach the AM workforce \& why?}

Following the design process framework outlined in Figure 1, seven speakers from industry

were invited to present their "customer needs" of the future AM workforce. Each speaker discussed their perceived needs for AM education and training and outlined the characteristics of the "ideal AM engineer." The invited industry speakers represented a range of OEMs and end users (i.e., customers). The industry speakers included:

- Mr. Perry Morissette from Boeing-Vertical Lift started the industry session by sharing insight into their use of AM, which includes visual aids, prototypes, shop-aids, parts to evaluate fit-check, parts for functional testing, and finally, "fly away" parts. He suggested that AM adoption is currently hampered by limited knowledge and access to AM technology. To address this, he presented three levels of AM workforce education and training: (i) 
general AM training, (ii) engineer, and (iii) equipment technician. The characteristics of each of these levels is shown in Figure 2.

Boeing Defense, Space \& Security I Vertical Lift

\section{Workforce Education and Training}

- General AM training

- Definition of AM and Terminology

- Key Elements of AM - Design - Build - Post Process - Inspect

- AM Technologies and Materials

- Aerospace applications

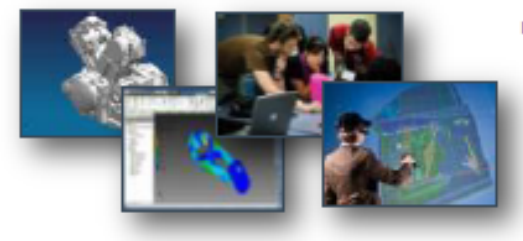

- Engineer

- Mechanical Engineering \& Material Science

- CAD modeling techniques

- Design Considerations \& Optimization

- AM Design Strengths and Weaknesses

- Equipment Technician

- AM Technologies and Materials (in-depth)

- Digital File Management

- Configuration Control, Formats, Manipulation \& Repair

- Post Processing

- Equipment Maintenance

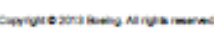

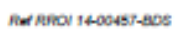

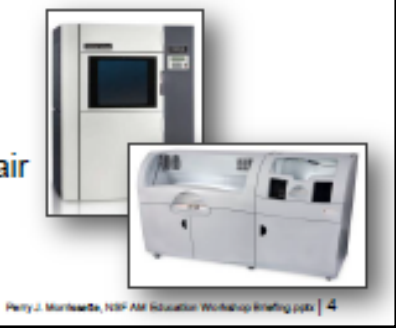

Figure 2. Examples of Boeing's AM Workforce Education Needs (Source P. Morrisette)

Mr. Morissette closed his talk with his vision for the "ideal AM engineer", i.e., a person who (i) is excited about $\mathrm{AM}$ and seeks opportunities for educating and promoting $\mathrm{AM}$, (ii) understands that "complexity is free" in AM, (iii) forgets the constraints of conventional fabrication and assembly, and (iv) uses systems engineering, design of experiments, and root cause and corrective action (RCCA) methodologies in their projects. He also ended with a quote from one of his engineers stating that "AM will become less of a nicety and more of a necessity", which captured where many felt AM is heading in the very near future. 
- Mr. Jay Beversdorf from Stratasys shared insight into how their customers use AM to create jigs and fixtures, tooling, and end-use parts (see Figure 3). He then presented his perceived barriers to AM adoption, which include: (i) poor understanding of AM capabilities, and (ii) AM not considered early on in product development. To address these barriers, he suggested that an AM curriculum should provide students with an understanding of traditional manufacturing processes as well as the fundamentals of AM. He stressed the importance of teaching students how to design parts for AM and using AM to solve engineering problems. He said the ideal AM engineer would embrace innovation and be willing to try new opportunities and ideas enabled by AM.

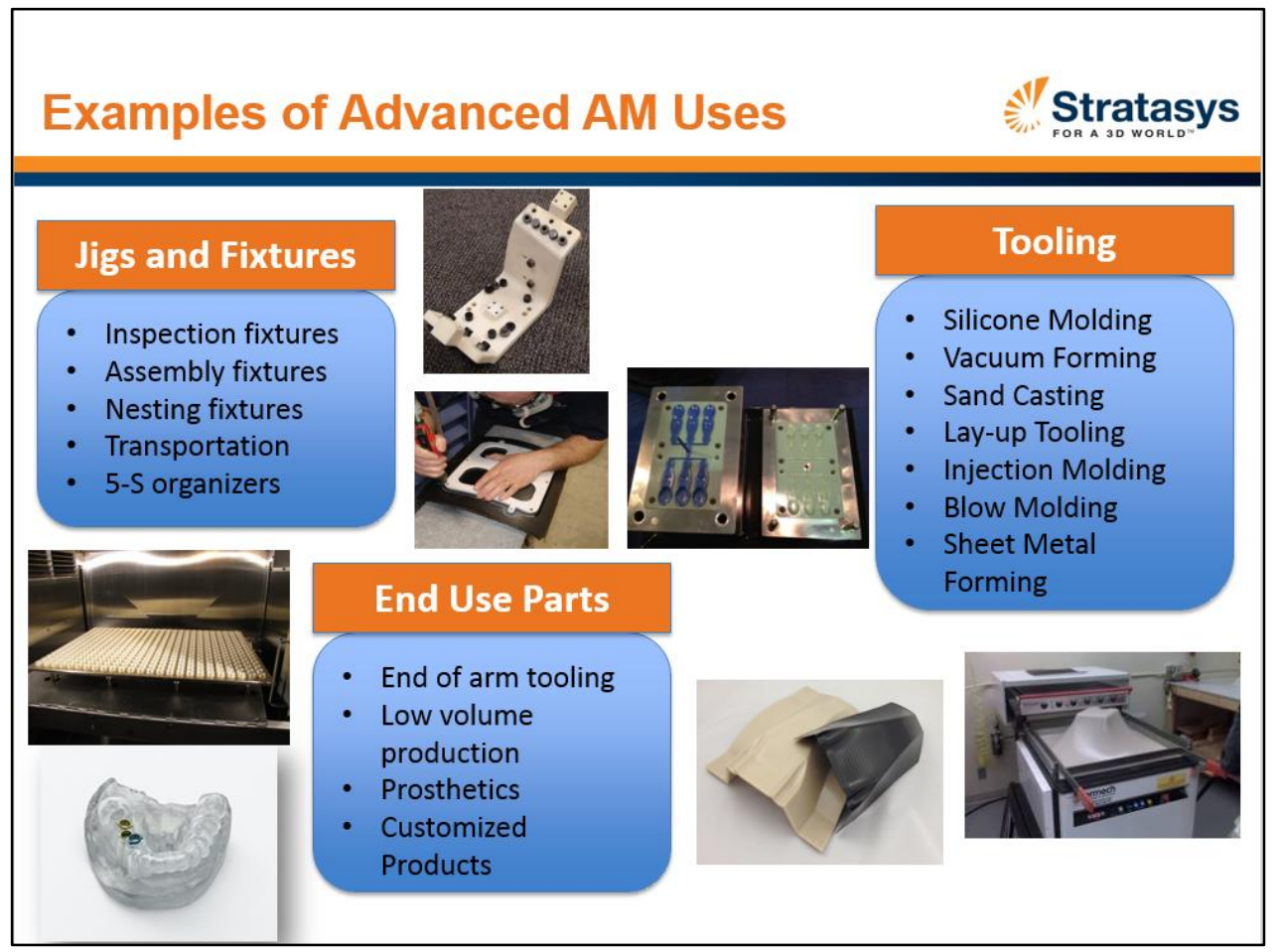

Figure 3. Examples of AM Uses by Stratasys's Customers (Source J. Beversdorf)

- Dr. Shawn Kelly, the Director of the AM Consortium at EWI, stated that the technical barriers to AM adoption include insufficient quality, lack of qualification and certification 
approaches, lack of AM-specific design considerations, and material science issues. Poor understanding of AM process limitations and an overall lack of AM training are additional barriers. Even though AM provides considerable design freedom compared to existing manufacturing processes, he stressed that downstream considerations (e.g., inspection, certification, quality control, material properties) warrant a more "holistic view of AM" as shown in Figure 4. Given his expertise in laser-based AM processes, he stressed the need for an enhanced knowledgebase of welding metallurgy, materials science, and heat transfer (and related material distortion) for metallic applications of AM. He stated that the ideal AM engineer not only understands the AM manufacturing chain and process capabilities, but also understands materials science and metallurgy, how the process affects the material quality and properties, and engineering design.

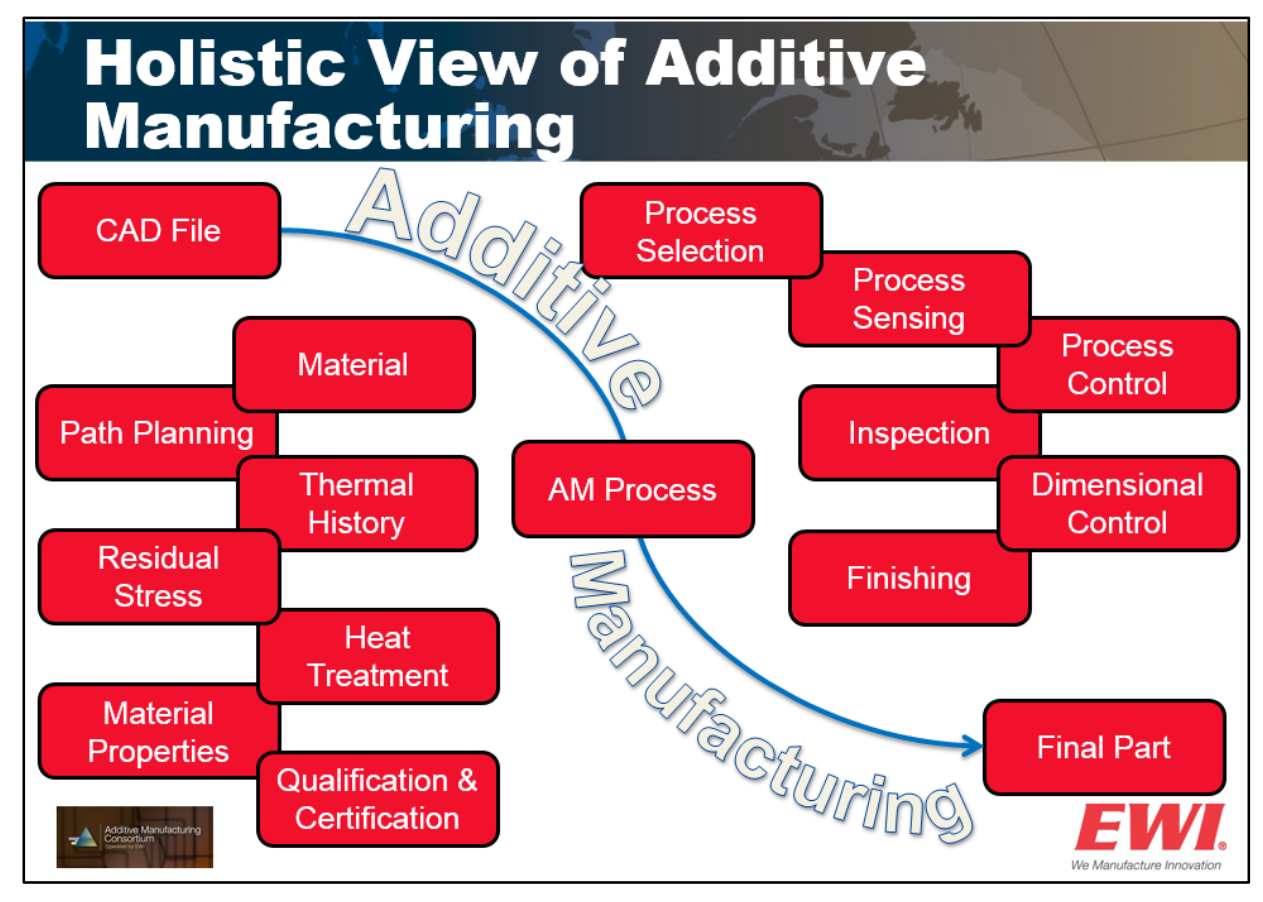

Figure 4. A "Holistic View of AM" Topics (Source S. Kelly)

- Mr. Philip Lane from ExOne shared the OEM's needs for future AM engineers. He expressed a need for an AM workforce that featured materials science researchers, engineers 
for part design and analysis, and technicians for post-processing, part testing, printing, and part inspection, verification and validation. The specific needs for each of these positions is summarized in Figure 5. Mr. Lane stressed that the ideal AM engineer understands and takes advantage of the relationships between materials, part design, and the selected AM process.

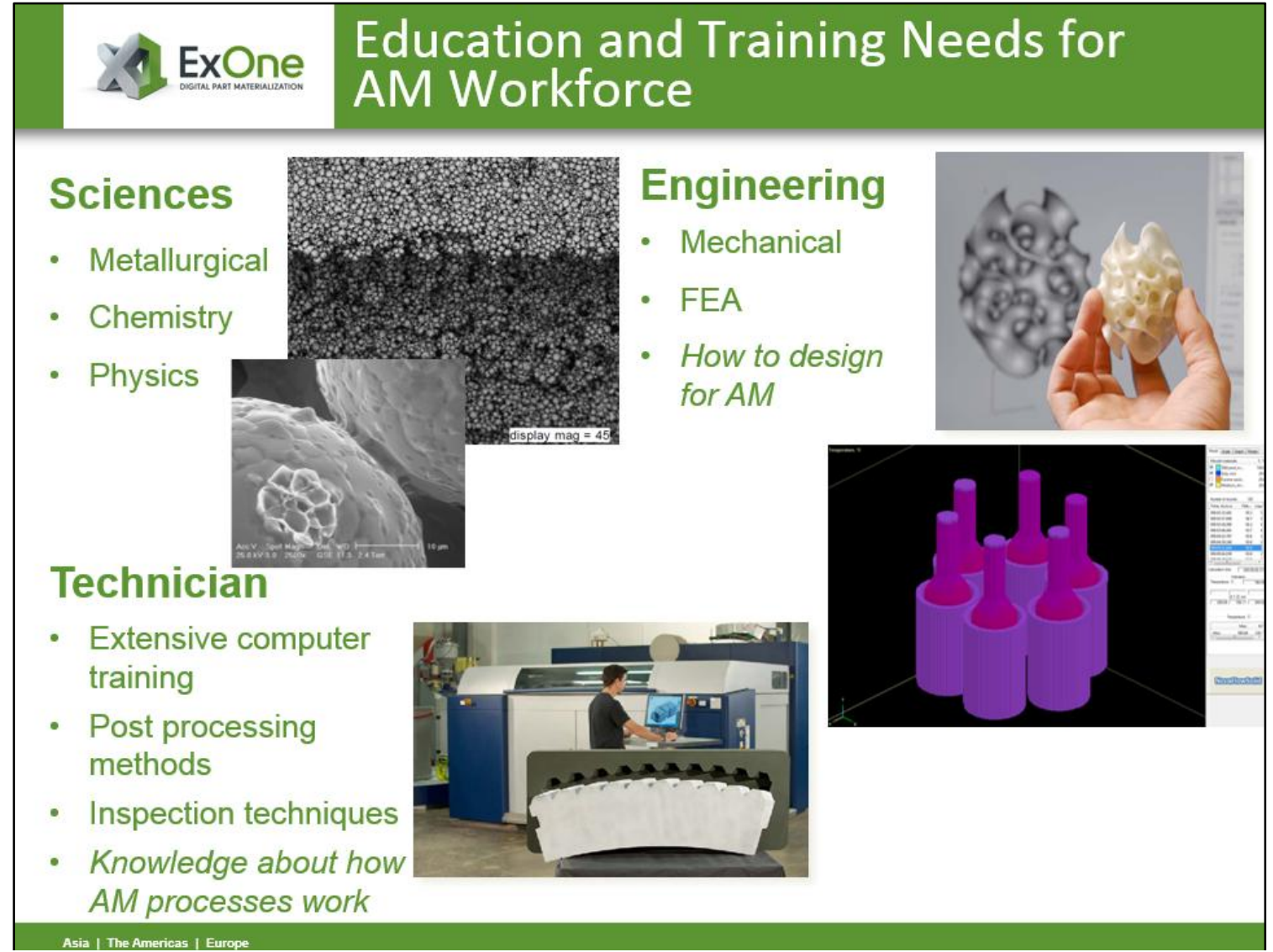

Figure 5. ExOne's Workforce Needs for Various Industry Positions (Source P. Lane)

- Mr. Bill Flite from Lockheed Martin highlighted some of the company's advanced uses of AM, which include titanium fuel tanks for spacecraft. In addition to an overall lack of ubiquitous knowledge and awareness of AM technologies, Mr. Flite suggested that barriers to AM implementation include a lack of closed-loop process control, insufficient material design allowables, and lack of aerospace-qualified materials and processes. He stressed that 
"Design for AM" techniques, which include design and analysis guides and methods for selecting (and costing) appropriate AM technologies, need to be prominent in future AM curricula. He also suggested that, in addition to training the future workforce, we re-train and re-educate both experienced engineers and shop-floor technicians in how to design for, and support, AM. For Lockheed Martin, the "basic" knowledge required to be an AM engineer lies in the topics of design for manufacturing, CAD, and AM process basics. Advanced skills include polymer chemistry, metallurgy, and topology optimization. In addition to these skills, the ideal AM engineer would have a "maker" mentality and see value in iterative design.

- Mr. Andrew Lucibello from EOS highlighted their polymer and metal AM systems and their applications, which entail medical (e.g., dental, orthopedic devices, surgical implants) and aerospace (e.g., jet engine fuel injection systems, air ducts for plane cabins, unmanned air vehicles - see Figure 6). He used these examples to inform the audience that the future AM engineering workforce needs to be made aware of the possibilities AM offers to its users including expanded design freedom, enhanced productivity (via rapid prototyping), reduced cost (via integrated functionality and assembly reduction), and product customization. 

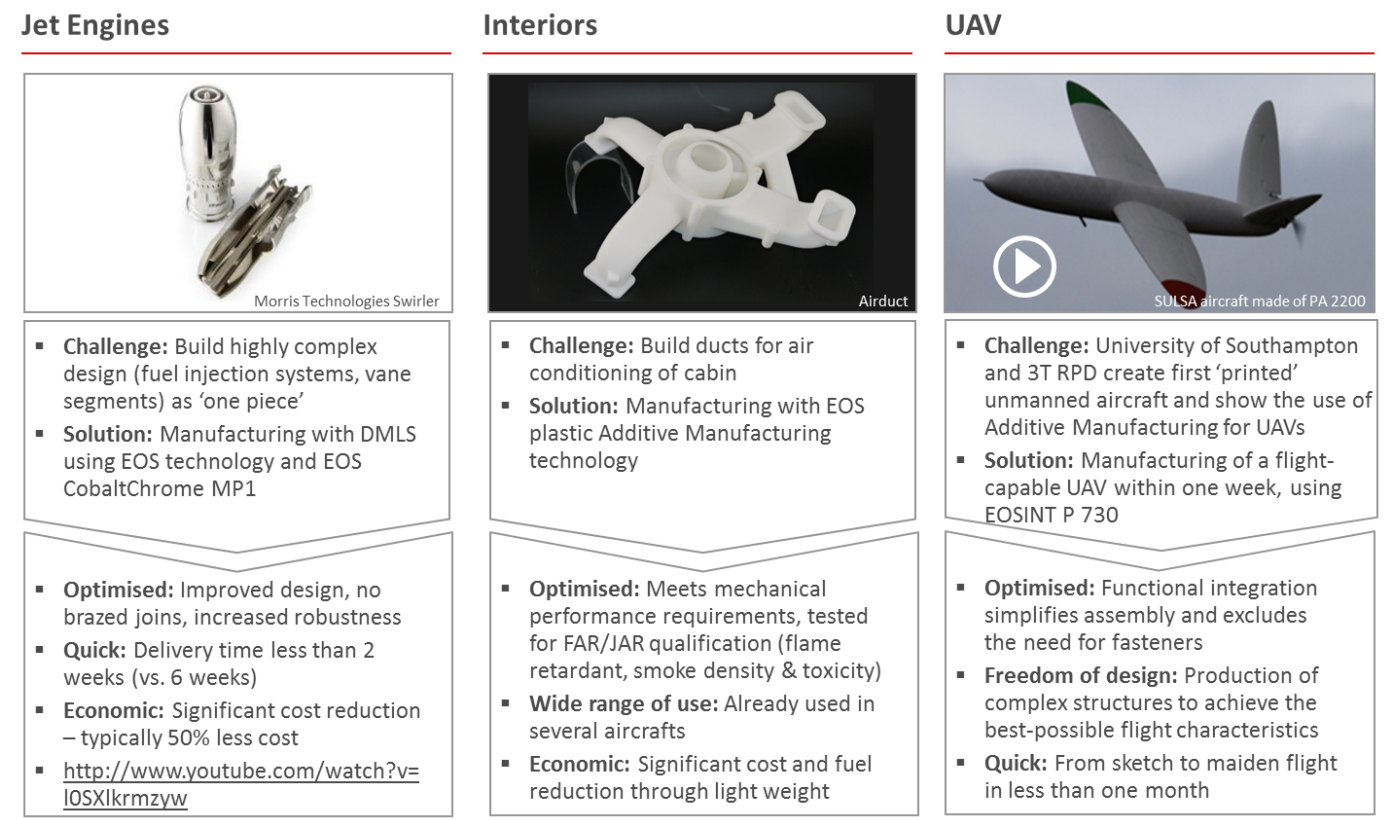

Figure 6. Examples of EOS Aerospace Applications and AM Benefits (Source A. Lucibello)

- Dr. Ola Harrysson from North Carolina State University presented on behalf of Arcam, an

OEM that produces Electron Beam Melting (EBM) equipment. In addition to the current technical limitations of absence of adequate part validation, insufficient understanding of material properties, and overall high costs, Dr. Harrysson also stated that the need for engineers and technicians with sufficient AM skills were barriers to AM adoption. He delineated educational requirements for four AM-related careers: (i) machine operators who would require a technical degree that would be focused primarily in customer interactions and providing extensive experience with AM machines; (ii) application engineers who require a M.S. degree to understand the technical skills, materials knowledge, and the necessary software tools (e.g., CAD, file preparation, and build preparation); (iii) service technicians who would require a B.S. in engineering to provide them knowledge of the necessary software tools for the AM build cycle (e.g., CAD, file preparation, and build preparation); and (iv) research \& development personnel who would require a Ph.D. in 
engineering or material science to help enhance the overall AM process and material portfolio. He closed his talk by suggesting that the ideal AM engineer would be a wellrounded engineer that had good technical skills and a good understanding of material behavior-and was meticulous and very safety conscious.

The slides from each industry presentation can be found on the workshop website [12].

Despite their different contexts, many similar themes emerged from their presentations. A Wordle based on the text of their slides was created to synthesize these themes (see Figure 7). The graphic word cloud displays those words that appeared more frequently in the presentations with greater prominence. As can be seen in the figure, speaker topics in design, engineering, process, manufacturing, technologies, and material appeared repeatedly in the presentations, providing a common point for the small group discussions that followed.

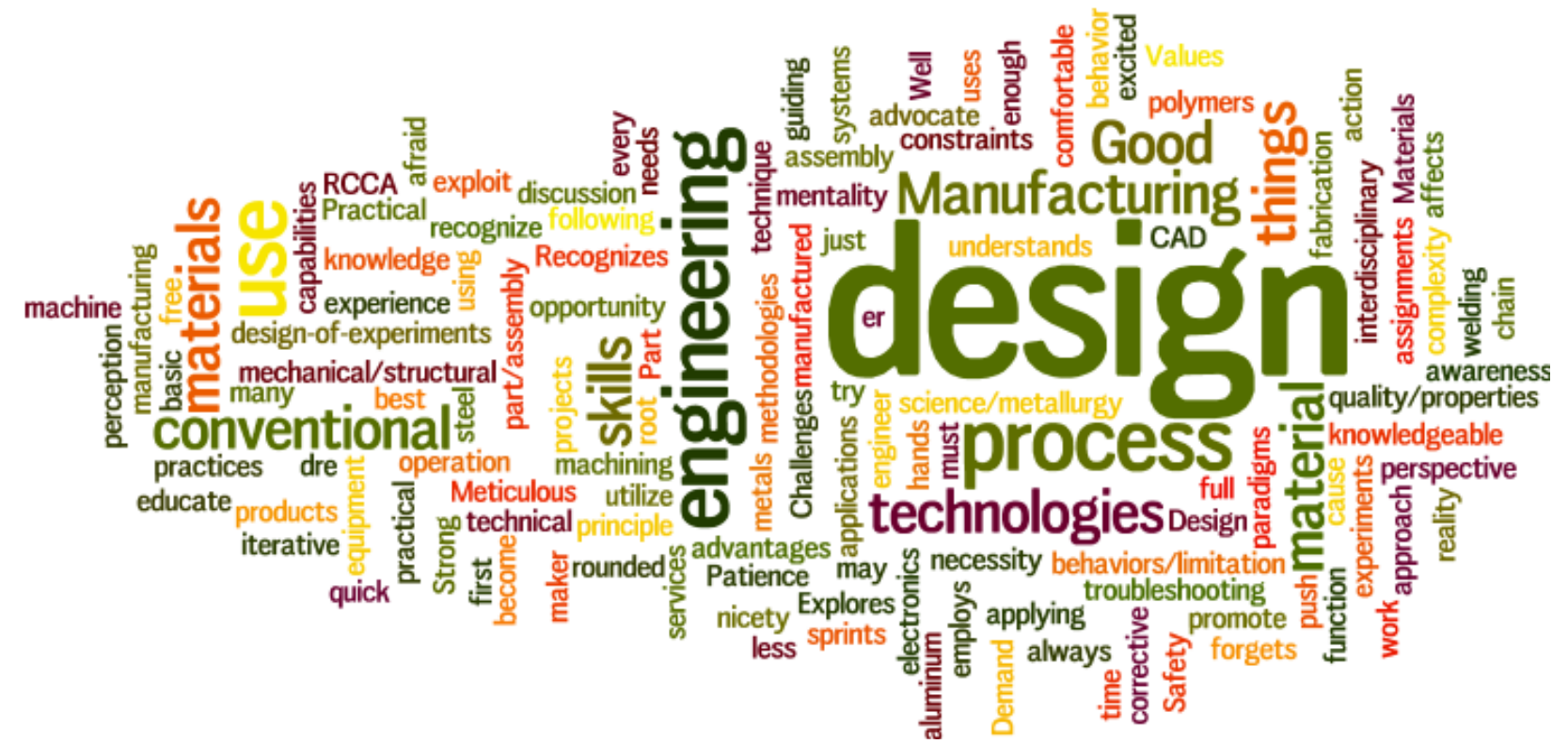

Figure 7. Common Topics across the Industry Speaker's Presentations via Wordle

Using the industry speakers' presentations as a foundation, participants were placed into small groups of 6-8 people, and were asked to respond to the following question: "What should 
we teach to the AM workforce and why?. Each group was strategically formed a priori to ensure that each group had representation from industry, academia, and the government. The participants worked in their groups (see Figure 8) and used mind maps (see Figure 9) to ideate topics that they perceived to be relevant to AM curricula across all levels and domains.

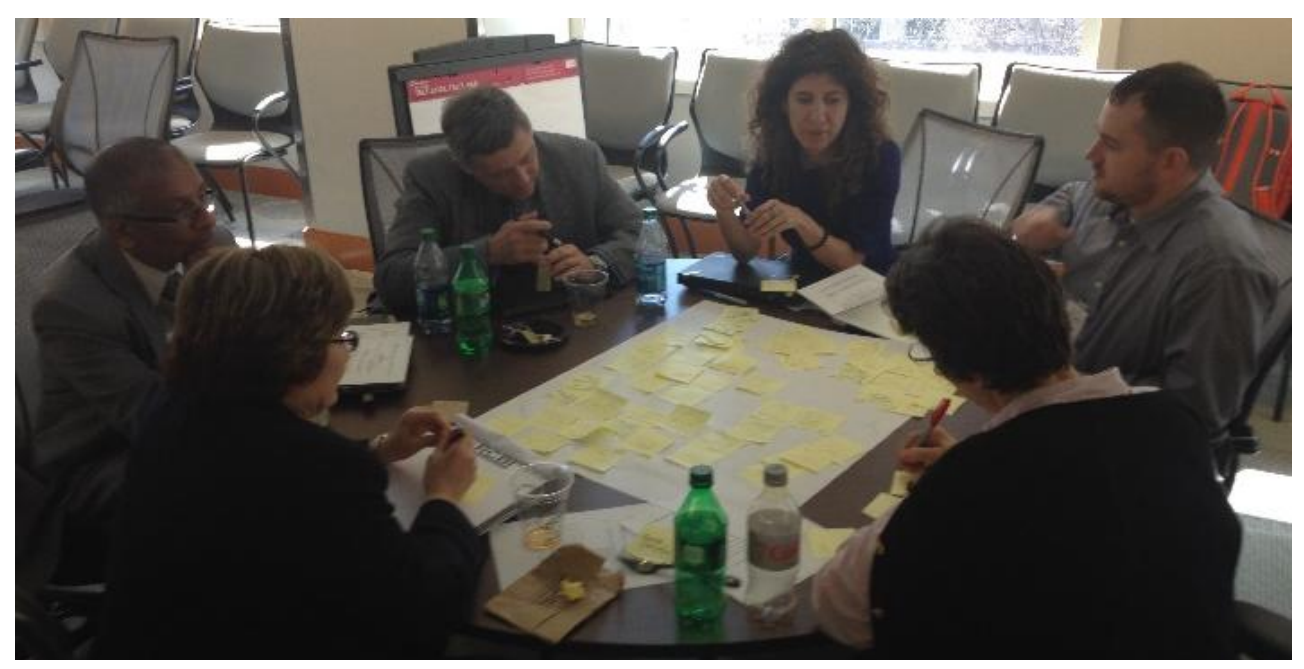

Figure 8. Small Groups Ideate Topics for AM Curriculum and Training

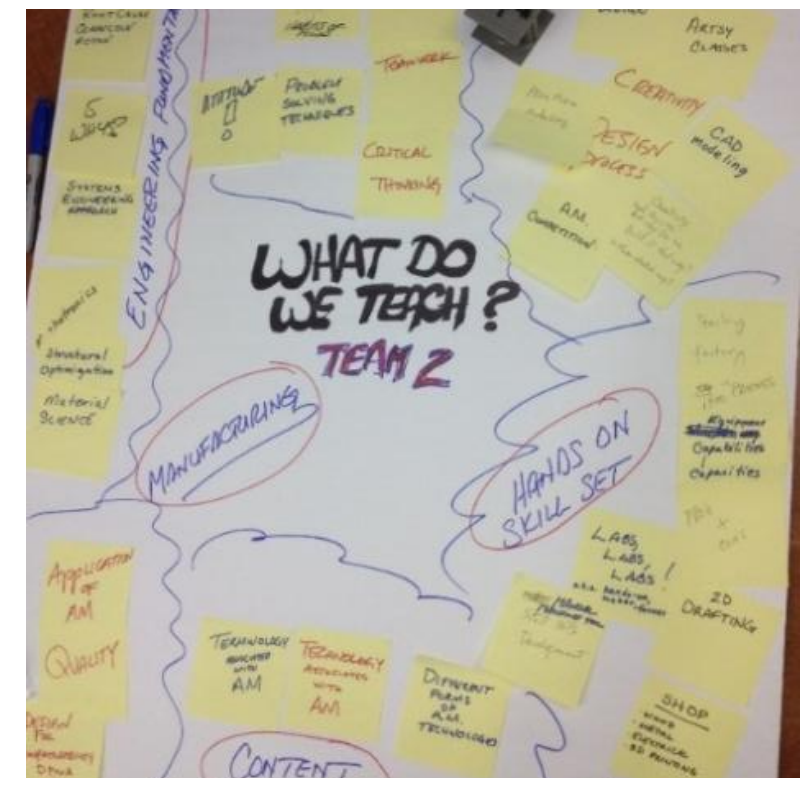

Figure 9. Example of Mind Map from Small Group Discussion

Following the small group discussions, we surveyed and tallied all of the items on each of the group's mind maps to identify reoccurring topics and themes (see Table 1). All of the individual 
topics can be broadly grouped into five key themes (listed in order of highest frequency count, which is indicated in parentheses), as follows.

Table 1. Summary of AM Topics and Frequency of Appearance on Group's Mind Maps

\begin{tabular}{|c|c|c|}
\hline & Topic & Freq. \\
\hline \multirow{5}{*}{ 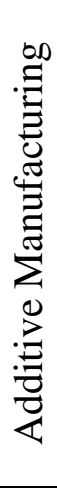 } & $\begin{array}{l}\text { Terms, processes \& } \\
\text { technologies, pros \& cons }\end{array}$ & 40 \\
\hline & $\begin{array}{l}\text { Business considerations: supply } \\
\text { Chain, economics, lifecycle } \\
\text { analysis \& sustainability }\end{array}$ & 21 \\
\hline & Design for AM; File formats & 16 \\
\hline & $\begin{array}{l}\text { AM Materials \& Material- } \\
\text { Process relationships }\end{array}$ & 13 \\
\hline & $\begin{array}{l}\text { Knowledge about applications, } \\
\text { successes \& careers }\end{array}$ & 6 \\
\hline \multirow{12}{*}{ 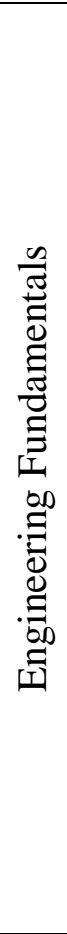 } & $\begin{array}{l}\text { Material science; computational } \\
\text { mechanics; metallurgy; material } \\
\text { selection; polymer chemistry }\end{array}$ & 19 \\
\hline & $\begin{array}{l}\text { Manufacturing technologies: } \\
\text { overview of traditional } \\
\text { processes (machining), nano }\end{array}$ & 16 \\
\hline & $\begin{array}{l}\text { Metrology, Quality Control, } \\
\text { Testing and inspection, } \\
\text { Verification \& validation }\end{array}$ & 13 \\
\hline & $\begin{array}{l}\text { Engineering modeling, analysis, } \\
\text { \& statistics }\end{array}$ & 8 \\
\hline & Systems thinking & 6 \\
\hline & Math & 6 \\
\hline & Vocational / hands-on skills & 6 \\
\hline & Mechatronics & 1 \\
\hline & Engineering economics & 1 \\
\hline & Programming & 1 \\
\hline & Biomedical & 1 \\
\hline & Safety & 1 \\
\hline
\end{tabular}

\begin{tabular}{|c|c|c|}
\hline & Topic & Freq. \\
\hline \multirow{9}{*}{ 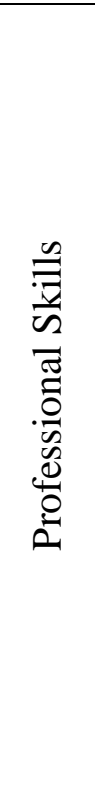 } & $\begin{array}{l}\text { Problem solving \& critical } \\
\text { thinking }\end{array}$ & 11 \\
\hline & $\begin{array}{l}\text { Teaming \& collaboration; } \\
\text { Cultural awareness }\end{array}$ & 10 \\
\hline & $\begin{array}{l}\text { Entrepreneurship, technology } \\
\text { transfer; Customer service \& } \\
\text { marketing }\end{array}$ & 10 \\
\hline & $\begin{array}{l}\text { Learning how to "Fail } \\
\text { Forward" }\end{array}$ & 7 \\
\hline & $\begin{array}{l}\text { Achieving breadth and depth: a } \\
\text { "T-shaped" engineer or a "da } \\
\text { Vinci" }\end{array}$ & 2 \\
\hline & Decision making & 2 \\
\hline & Teaching skills & 1 \\
\hline & Communication & 1 \\
\hline & Adaptability & 1 \\
\hline \multirow{7}{*}{ 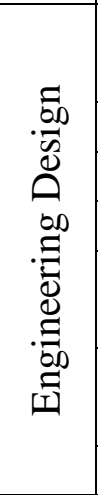 } & $\begin{array}{l}\text { Computer Aided Design } \\
\text { Software }\end{array}$ & 22 \\
\hline & Design Process & 13 \\
\hline & Topology Optimization & 3 \\
\hline & Finite Element Analysis & 3 \\
\hline & $\begin{array}{l}\text { Quality Functional } \\
\text { Deployment }\end{array}$ & 1 \\
\hline & $\begin{array}{l}\text { Geometric dimensioning \& } \\
\text { tolerancing }\end{array}$ & 1 \\
\hline & Reverse engineering & 1 \\
\hline \multirow{2}{*}{ 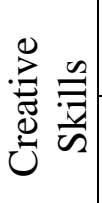 } & $\begin{array}{l}\text { Art, Industrial Design, } \\
\text { STEAM, art for designers }\end{array}$ & 6 \\
\hline & $\begin{array}{l}\text { Ideation / creativity techniques } \\
\text { / design thinking }\end{array}$ & 6 \\
\hline
\end{tabular}

- Additive Manufacturing (96): Participants placed significant importance on educating students on the basics of all AM processes and the AM process/materials relationships so that they may be able to effectively select AM processes for a variety of applications. 
- Engineering Fundamentals (59): Several participants expressed a need to continue to educate students in the fundamentals of engineering analysis, but with added emphasis on material science (to be able to better understand process/material interactions) and on manufacturing technologies (to be able to better select amongst traditional and additive manufacturing processes).

- Professional Skills (45): Participants expressed a need to educate students in problem solving and critical thinking skills so as to enable them to better address the needs of this advanced manufacturing technology. In addition, participants suggested that future AM curricula include content related to entrepreneurship and technology transfer.

- Design (44): Recognizing that AM significantly reduces the design constraints that are typically imposed by conventional manufacturing technologies, several participants stressed the need for integrating design into the curriculum. Many stressed the need for advancing students' understanding of CAD, FEA, and topology optimization software, as well as the design process.

- Creative Skills (12): Related to design education, many participants suggested that opportunities for nurturing students' creativity be included in a curriculum by teaching creativity techniques and integrating industrial design.

The small group discussions, in concert with the industry speakers' presentations, suggested that an AM curriculum should provide students an understanding of:

i. both $\mathrm{AM}$ and traditional manufacturing processes to enable them to effectively select the appropriate process for product realization; 
ii. a formalized "Design for AM" process that includes both AM-specific computational tools (e.g., CAD, FEA, topology optimization) and frameworks for process selection, process costing, and generating novel solutions that take advantage of AM capabilities; and

iii. the relationships between manufacturing processes and material properties.

In addition to these technical topics, an AM curriculum would prepare students to work well as part of a team, provide a breadth of knowledge to be able to adapt to new challenges as they arise, and encourage them to take risks and learn from design iterations that leverage AM.

\subsection{To whom, where, and how should we teach AM?}

Having worked collaboratively to ideate what we should teach the AM workforce, the next task was to identify how we should educate and train the workforce. To accomplish this objective, academic speakers were invited to give "lightning talks" on "best practices" for delivering AM education. Due to time constraints, only eight speakers were invited to speak; however, a total of 12 academic participants submitted PowerPoint slides that highlighted their work in the classroom. All of these slides can be found on the workshop website [12]. Examples of the AM educational "best practices" included:

- Dr. Carolyn Seepersad (Mechanical Engineering, University of Texas-Austin): The core of UT-Austin's AM offering is an undergraduate/graduate AM course that provides students an understanding of (i) alternative AM processes, capabilities, and limitations, (ii) economics and sustainability of $\mathrm{AM}$, and (iii) a design process for $\mathrm{AM}$, including applications and emerging trends. The course [14] is based on a project- and problem-based pedagogy and culminates in a semester-long "Design for AM" project, in which students are tasked with designing a product specifically for AM. Dr. Seepersad suggested that "Design for AM" 
knowledge might be more critical than AM process knowledge, as parts that make effective use of the technologies' capabilities can drive demand for AM.

- Dr. Rahul Rai (Mechanical \& Aerospace Engineering, University at Buffalo-SUNY): Students learn about AM by investigating the functional components of AM through dissection of an AM system and developing process-flow software. In the undergraduate/graduate elective course on AM, students work on developing an AM embedded system; as a result, the students become exposed to both hardware and software issues related to AM. Learning objectives of the course include: providing understanding of the basic AM principles and underlying process physics, comparing and selecting AM processes, and developing handson, teamwork, and problem solving skills by applying AM techniques in a design problem.

- Dr. David Rosen (Mechanical Engineering, Georgia Tech): Georgia Tech's AM educational initiatives feature both formal (e.g., a dedicated AM class) and informal (e.g., the "Invention Studio" maker space) learning environments. GT's Invention Studio (see Figure 10) is a student-led maker space that features multiple digital fabrication tools (e.g., $\sim 203 \mathrm{D}$ printers, 3 laser cutters, a water-jet cutter, CNC, etc). The Invention Studio, which aims to (i) inspire innovation, design and "making", (ii) provide opportunities for student leadership and (iii) provide fabrication resources for senior capstone design projects, serves over 700 students per semester. Dr. Rosen stated that it has fed a culture of entrepreneurship and innovation across the campus. Dr. Rosen also shared information on their AM course's learning objectives. Specifically, upon completing their AM course, students should be able to: (i) select the appropriate AM technology, (ii) analyze AM processes to determine the effects of 
changing process variables, (iii) understand the unique capabilities of AM technologies and demonstrate the ability to take advantage of them, (iv) apply AM technologies appropriately in an engineering design-manufacture context, (v) demonstrate the ability to design process chains that include AM technologies, and (vi) understand the state-of-the-art in AM research.

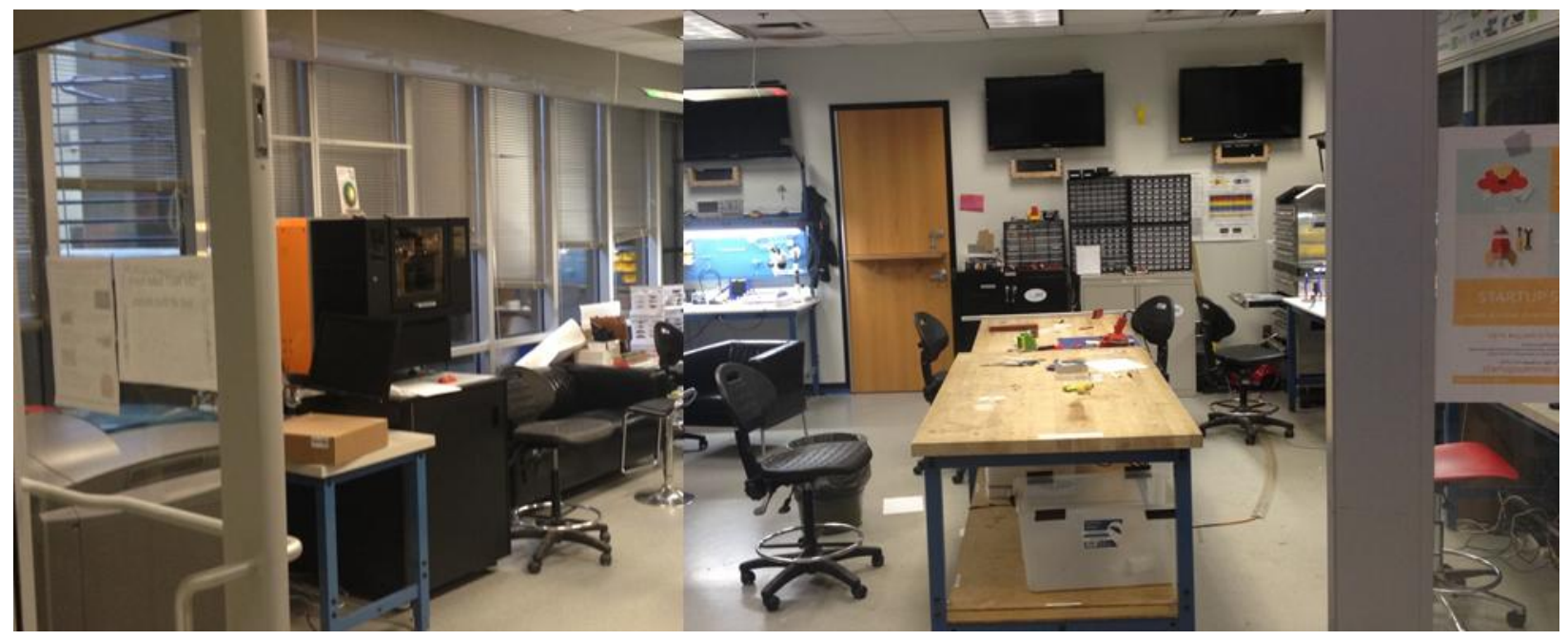

Figure 10. Georgia Tech's Invention Studio (Source D. Rosen)

- Dr. Krishnan Suresh (Mechanical Engineering, University of Wisconsin-Madison): To leverage the design freedoms of AM, Dr. Suresh discussed topology optimization and new software his team was creating. The software, PareTOWorks, is integrated into SolidWorks for ease of use, and the output STL file is directly 3D printable. As part of his presentation, he showed a video that demonstrated the software interface and use. PareTOWorks can be downloaded free from their website and is currently being deployed in over two dozen universities across the world. In the future, Dr. Suresh and his team plan to integrate this and related design software into a summer-school course that focuses on "Digital Design and Manufacturing", targeting graduate students, post-docs, and faculty as well as practicing engineers. The course will provide the fundamentals of digital design tools, include handson workshops, and discuss open research opportunities in AM. 
- Dr. Richard A. Wysk (Industrial \& Systems Engineering, NC State): Driven by a changing digital paradigm for manufacturing, NC State developed a new three-course manufacturing sequence (see Figure 11) that covers (i) design and prototyping, (ii) traditional manufacturing processes, and (iii) contemporary manufacturing systems. The course sequence features a "flipped classroom" (i.e., students watch pre-taped lectures out-of-class and spend in-class time solving problems, case studies, and open-ended design problems) and hands-on laboratories. In addition to this undergraduate three-course sequence, NC State features a graduate-level introductory course in manufacturing, which provides the necessary background to take more advanced courses in additive manufacturing, medical-related manufacturing, micro/nano-manufacturing, automation, and production engineering.

\begin{tabular}{|c|c|c|}
\hline $\begin{array}{l}\text { Course } 1 \\
\text { This course will teach the students } \\
\text { the process of going from a product } \\
\text { idea to a functional prototype } \\
\text { - Topics to be covered } \\
\text { - Market research, voice of customer, } \\
\text { QFD, and concept generation and } \\
\text { selection } \\
\text { - Basic detailed design using } \\
\text { Solidworks and other appropriate } \\
\text { software } \\
\text { - Geometrical Dimensioning and } \\
\text { Tolerancing, Metrology } \\
\text { - The use of Additive Manufacturing } \\
\text { technologies to fabricate conceptual } \\
\text { and functional prototypes } \\
\text { - Metrology/Qualification }\end{array}$ & $\begin{array}{l}\text { Course } 2 \\
\text { The following course will teach } \\
\text { the students about the different } \\
\text { manufacturing processes that can } \\
\text { be used to mass-produce the } \\
\text { product } \\
\text { - Topics to be covered } \\
\text { - Modern manufacturing } \\
\text { processes } \\
\text { - CNC, Injection Molding, } \\
\text { Micro and Nano fabrication } \\
\text { - Process limitations, costs and } \\
\text { DFX } \\
\text { - Automation necessary for } \\
\text { modern manufacturing } \\
\text { - Geometric tolerancing }\end{array}$ & $\begin{array}{l}\text { Course } 3 \\
\text { - Manufacturing Systems } \\
\text { Engineering: design of } \\
\text { contemporary manufacturing } \\
\text { systems } \\
\text { - Topics to be covered } \\
\text { - Elements of lean manufacturing } \\
\text { - Automation and control } \\
\text { - Integrate manufacturing } \\
\text { processes with automation for } \\
\text { part handling and inspection } \\
\text { - Hands on projects for system } \\
\text { design and implementation }\end{array}$ \\
\hline
\end{tabular}

Figure 11. NC State's Three-Course Sequence in Manufacturing (S. R. Wysk)

- Dr. Karen Wosczyna-Birch (NSF ATE Center for Next Generation Manufacturing): This ATE Center offers AM initiatives targeting students at both K-12 and community college levels. The Center offers an AM Manufacturing Certificate consisting of four courses targeted at training community college students in AM. Courses feature an overview of AM technology and processes, and detail the process parameters needed to ensure a high-quality part. Their 
3D Manufacturing by Design Curriculum targets high school and community college students and provides an understanding of how to design, make, and market 3D models via AM. The course features a design project that challenges students to create a $3 \mathrm{D}$ printed object that meets a need or solves a common problem found in the home. Finally, a middle school initiative, CPEP Ventures, focuses on engaging urban-under-represented students that uses desktop 3D printers to stimulate research, development, and manufacturing experience. Their program is moving AM forward by targeting both science, community college, and university faculty and students in the areas of science, technology, engineering, arts, and math (STEAM).

- Christopher Williams (Mechanical Engineering, Virginia Tech): In addition to a formal AM course [14], Dr. Williams highlighted two informal AM learning initiatives: (1) a 3D printing vending machine and (2) a large extracurricular design competition (see Figure 12). The "DreamVendor" is a 3D Printing vending machine that allows students to fabricate parts for their personal and course-based design projects. The DreamVendor has engaged students at all levels from departments across the university [15]. In addition, VT has hosted an extracurricular design competition that challenged students to design remote-control air and ground vehicles that can be fabricated completely by AM [16]. The challenge engaged over 200 students across the university in its pilot offering [17]. 

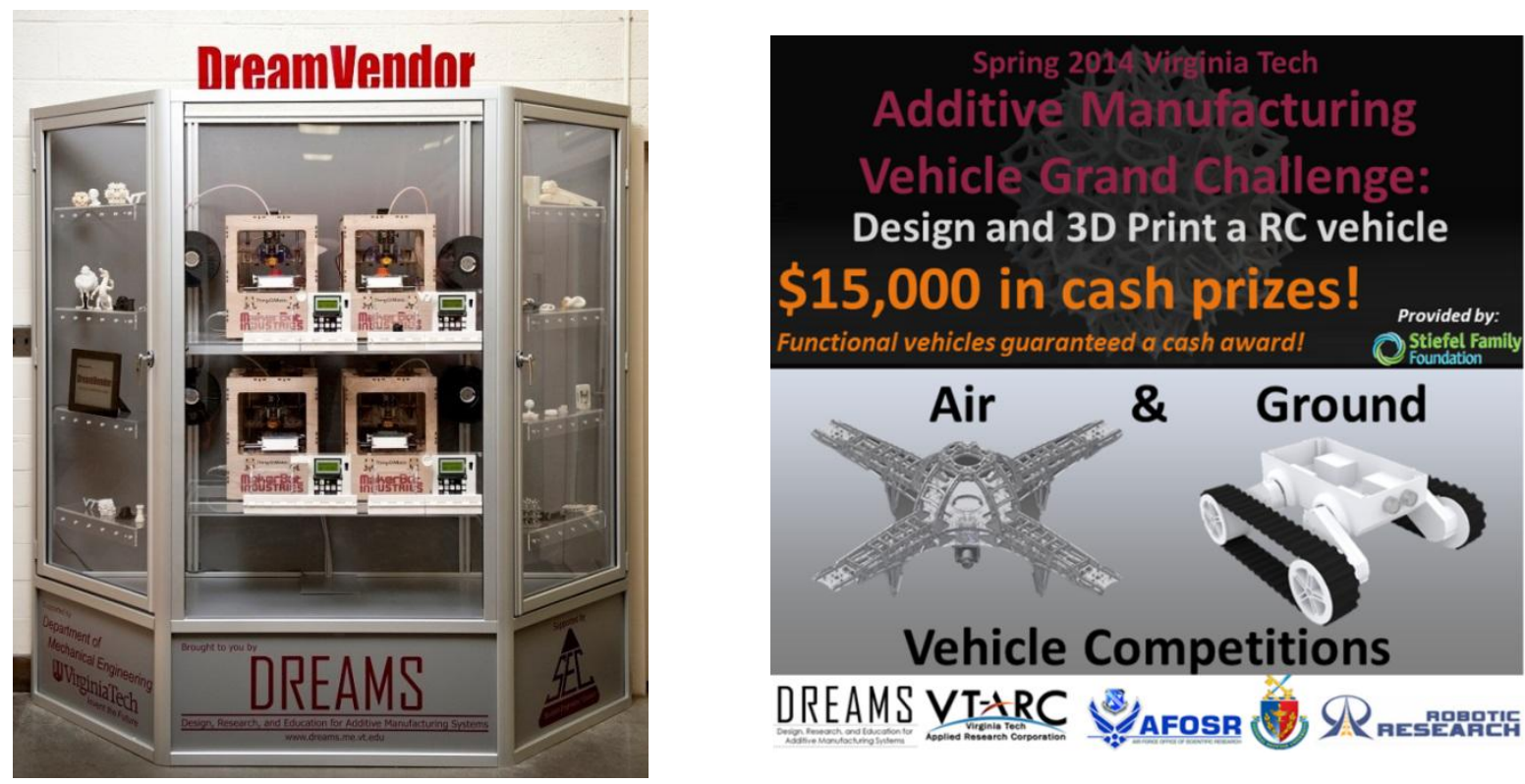

Figure 12. Virginia Tech's “DreamVendor” and AM Challenge (Source C. Williams)

\subsection{How should we partner?}

After the discussions of educational "best practices," workshop participants were then presented examples of the organization of national efforts in providing education on topics of advanced manufacturing. The nine speakers discussed activities supported by NSF and other government agencies as well as efforts by industry and non-profit organizations.

- NSF RapidTech Program: Established in 2007, the mission of NSF's RapidTech Program is to assist industry and educators with the adoption of rapid technologies such as 3D printing and additive manufacturing. Ed Tackett, Director of RapidTech, which is now hosted by the University of California-Irvine, discussed the differences in career pathways for high school, community college, and university students and shared how RapidTech provides "stackable and latticed" certificate programs and Associate of Science degrees to meet the different needs of these different students (see Figure 13). Five colleges are partnered in the effort and national workshops have engaged nearly 100 high schools, colleges, and universities in their 
educational efforts (see Figure 14). Almost 150 organizations have been involved with their industry workshops and workforce training programs.

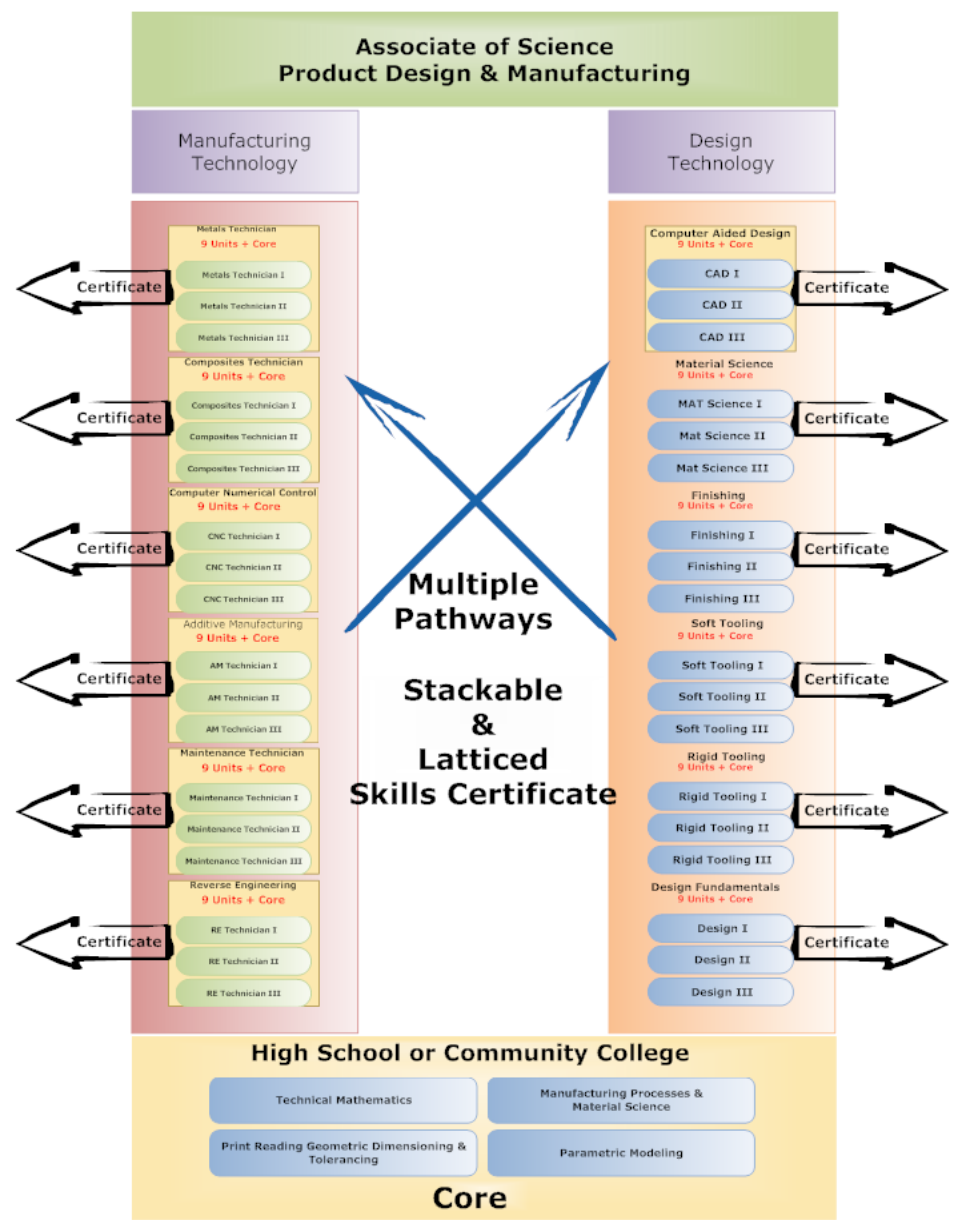

Figure 13. Stackable and Latticed Certificates and Degrees (Source E. Tackett)

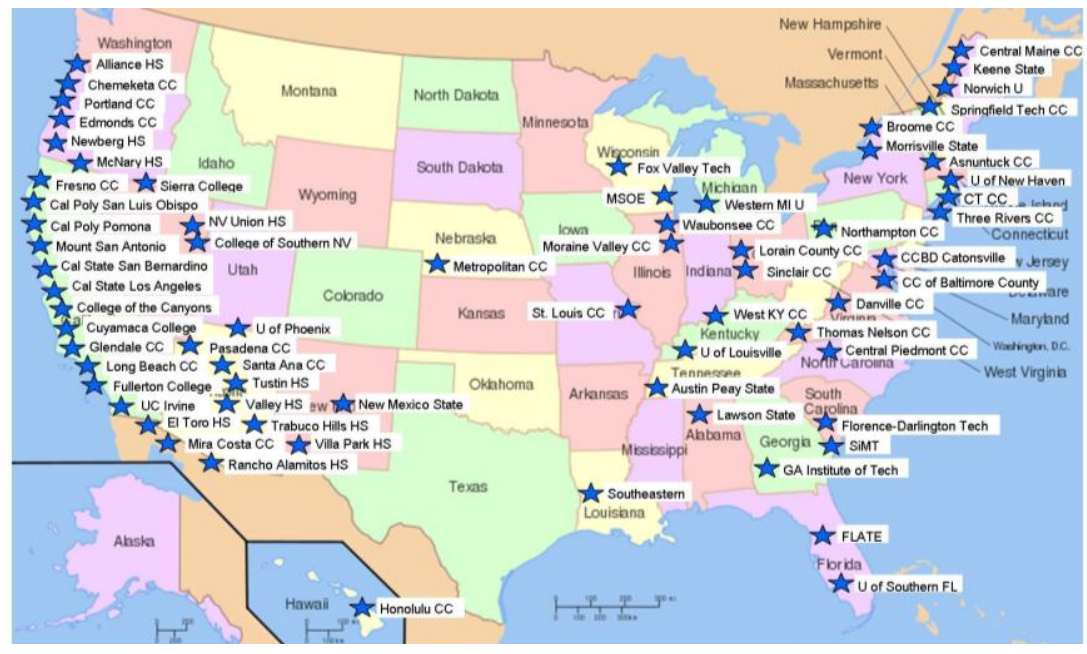

Figure 14. Attendees of RapidTech's National Workshops (Source E. Tackett) 
- NSF's Nanotechnology Applications and Career Knowledge Network (NACK): The mission of NACK is to enable nanotechnology education at two-year community and technical colleges in partnerships with four-year universities. This enables resource sharing (e.g., courses, programs, laboratory facilities, staff), which eases the staff and cost burden at community technical colleges that cannot afford high-end nanotechnology and creates educational pathways through and across institutions for student development. NACK engages research universities and community and technical colleges in 18 states and provides resources and services through a shared web portal (see Figure 15). Course materials and assessment rubrics are developed by university and industry practitioners, and lectures are available through the web in multiple formats (e.g., PowerPoint, video). Based on proximity and travel support, students from community and technical colleges can travel to university "hubs" for hands-on laboratories and capstone coursework; remote web access and videos of equipment operation are made available to those who cannot travel. More than 1,200 educators and practitioners have completed nanotechnology workshops, and more than 135 companies have hired students into micro/nanotechnology jobs.

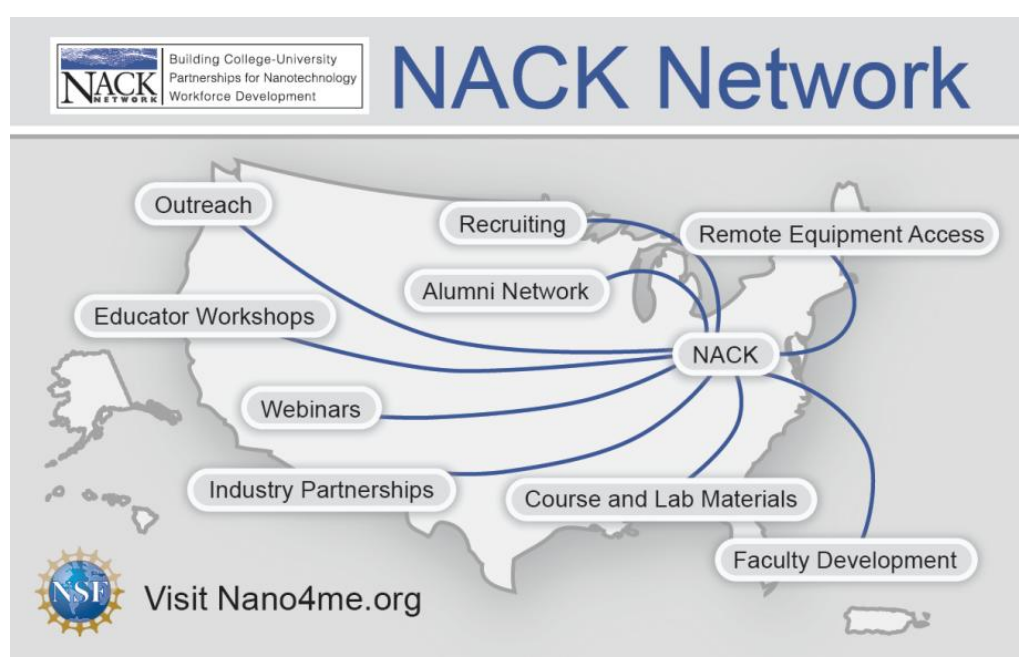

(a) Responsibilities distributed and shared through network

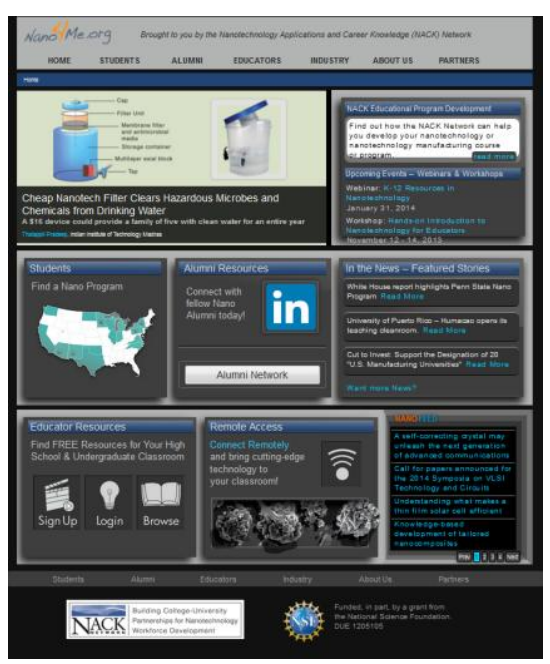

(b) Unified through web portal

Figure 15. NACK Reources and Services via http://nano4me.org (Source O. Awadelkarim) 
- American Society of Mechanical Engineers (ASME): ASME is developing new ways to engage its 130,000 members in support of AM and advanced manufacturing technologies. Brandy Smith, Program Manager for Emerging Technologies at ASME, shared information on the Advanced Design \& Manufacturing Impact Forum that ASME organized to coincide with the 2014 ASME International Design Engineering Technical Conferences in Buffalo, NY. Senior-level leaders and CEOs from MakerBot, Stratasys, Sciaky, Optomec, SLM Solutions, Solid Concepts, and many more shared their insights on the business of 3D printing and AM's future, while companies like Honeywell, Lockheed Martin, and Boeing discussed the challenges of adopting AM in their industry. ASME had previously developed video podcasts and assessment-based courses in support of nanotechnology education through their Nanotechnology Institute, and they welcome ideas for developing similar online materials for AM that they can host and globally through their membership.

- National Institute for Standards and Technology (NIST): NIST recognizes that AM is a multidisciplinary effort, and they are engaging numerous inter-agency working groups, federal agencies/labs, non-governmental organizations, public-private partnerships (e.g., America Makes), universities, and industries in their work. Dr. Paul Witherell, Project Lead for Systems Integration for Additive Manufacturing, gave an overview of the ongoing efforts in measurement science for AM within NIST's Engineering Laboratory. They are currently focusing on four areas critical for AM adoption: (1) characterization of AM materials; (2) real-time control of AM processes; (3) qualification of AM materials, processes, and parts; and (4) systems integration for AM. NIST offers opportunities for undergraduate, graduate, and post-graduate training grants through programs such as NIST's Summer Undergraduate Research Fellowship (SURF) program, which provides financial support and housing for the 
students. NIST is also involved in AM standards development through the American Society for Testing and Materials (ASTM) F42 Committee on AM Technologies.

- NextFab: Evan Malone (President) explained how his "gym for innovators" leverages its 3D printing and fabrication capabilities to provide AM education and training to a variety of audiences. Their mission is to make the public aware of AM, to make hands-on users independent operators of AM, and to help manufacturing professionals know when to use AM. Toward this end, they provide complimentary 1-2 hour courses to engage the general public to learn about their equipment and offer paid memberships to access and use their equipment, similar to TechShop and other "gym membership" models. Hands-on users (e.g., makers, designers, entrepreneurs) of the facility can sign up and pay for software and hardware tutorials that range from a few hours to a few days to gain proficiency with a desired technology. Finally, manufacturing processionals, particularly from small/mid-size enterprises, can pay a small fee to send groups of individuals to 2-4 hour short courses to see hardware and software demos and talk to NextFab staff about related technical and business issues. NextFab is currently seeking partners to help develop intensive AM courses to cover the SME AM Certification Rubric and create "Certified AM Machinists" with the depth of knowledge to apply AM for commercialization and in new applications.

The slides from each partnership presentation can be found on the workshop website [12].

Following these presentations, participants had a better understanding of example AM educational programs and existing models of large-scale educational initiatives. The participants were then divided into seven teams, each tasked with developing a proposal (in a 3-minute "pitch" presentation format) that detailed an innovative new program for additive manufacturing education and/or workforce training. This activity sought to synthesize all of the speaker 
presentations, mind mapping, and small group discussions into a set of recommendations for novel models for AM education and workforce development. Sample concepts for creating a novel AM educational partnerships follow.

- Additive Manufacturing (AM) Training Pyramid: Team 1 developed an education model that connects the entire educational spectrum, from K-12, to non-engineering students, to AM research and development (R\&D) activities (see Figure 16). Starting with K-12 students, the curriculum would focus on understanding and implementing AM capabilities, targeted to both STEM and non-STEM students. Following completion of this core curriculum, those seeking to become Engineers and Digital Artists would continue forward in an AM Learning Incubator environment, with a structured "Design for Additive Manufacturing" program. Subsequently, a Systems Engineer might study the Process/Supply Chain for Additive Manufacturing. Engineers and Technicians would continue to learn about operation, repair, and troubleshooting of AM equipment. Finally, R\&D experts would seek to discover and advance new hardware, software, and materials for AM.

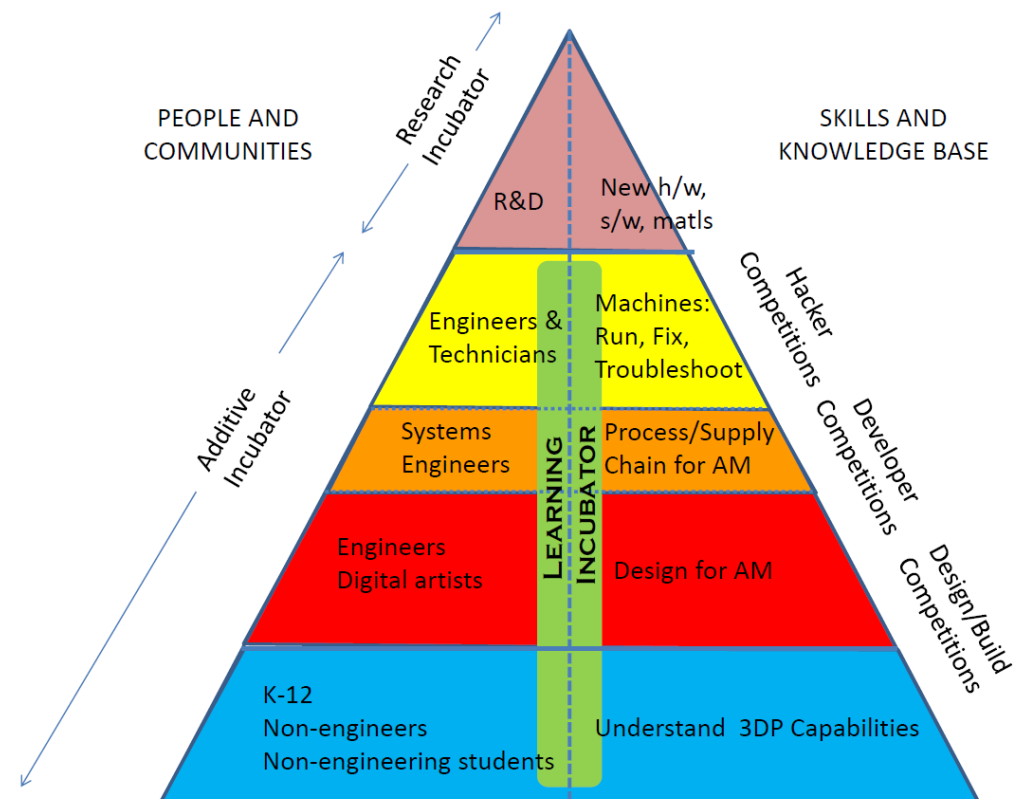

Figure 16. AM Training to Link AM Communities and Learning (Source: Team 1) 
- A National Network for Additive Manufacturing (AM) Education: Inspired by NSF's NACK Program, Team 2 proposed that a national network for AM education be established that integrates across three sub-networks comprised of virtual, physical, and human resources (see Figure 17). The national network for AM will provide a central clearinghouse for AM curricula, programs, and education resources. Furthermore, the suppliers could share resources for both educational content as well as physical labs and machines. Content is envisioned to be in the form of MOOCs, videos, seminars, and courses with powerful search engine and website design features to enable those looking for AM educational content to select from amongst a wide variety of attributes. The network would be established for both formal and informal learning environments across the educational spectrum (K-Gray). Strong partnerships are envisioned with industry, industry-government consortia (e.g., America Makes), professional organizations (e.g., ASME, SME), community colleges, K-12 schools, and universities.

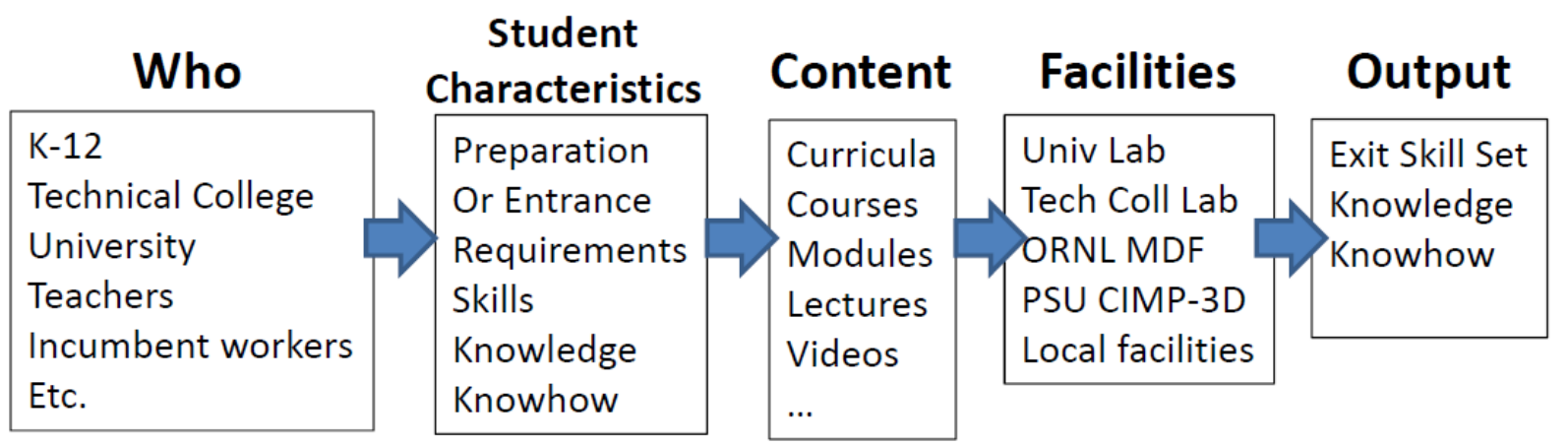

Figure 17. Schematic for A National Network for AM (Source: Team 2)

- MAKE-braries: Team 3 proposed combining maker spaces and libraries to create MAKEbraries, a $21^{\text {st }}$ century counterpart to Andrew Carnegie's leadership to establish libraries for every community in the late $19^{\text {th }}$ and early $20^{\text {th }}$ centuries. Each MAKE-brary would provide 
a funded community maker space in every community, equipped with a range of modern manufacturing tools (e.g., additive, subtractive, scanning, traditional shop tools).

- Enhance Current Workforce with AM After Hours: Team 6 sought to incorporate AM learning for current/incumbent workers, primarily professional engineers, designers, as well as their family members. Offering a mix of educational incentives, the intent would be to infuse AM into the organization via champions and provide immediate corporate value. These champions could help collect and share a company's manufacturing challenges with all of its employees. An AM "after-hours" build/use workshop, featuring a broad spectrum of desktop printers, located on or near the company premises would promote technology awareness and basic AM familiarity. Coupled with Lunch/Learn sessions, a company could familiarize employees with AM with little investment and minimal training cost. Moreover, the best AM solutions developed in the lab could be rewarded and incentivized with employee time off, pay bonus, or access to more low/no cost training. Multiple organizations from non-competing businesses could potentially share the "After Hours" workspace to help minimize cost and foster new collaborations and different perspectives. To offset the investment, the space could be shared with employee family members, the general public, or select student groups after hours.

- Integrated AM Activities for K-12 and Community Education: Team 7 advocated that AM education is inherently interdisciplinary, is at the forefront of national interest, provides a unique interconnectedness between STEM and the arts, is affordable, and offers good career prospects. As such, AM education provides a learning thread for lifetime education for all Americans, and they proposed activities spanning K-5 through parents. The K-5 focus would be on how things are made and how things work. Middle school students would develop 
creative thinking skills, and study AM software, hardware, chemistry, and materials. High school curriculum would include 3D printing tools, industry standards, and the business modeling required to understand when to employ an AM solution. Community colleges would teach factory skill for manufacturing to multiple-level users. Finally, AM education and awareness for parents is a critical educational component, to ensure support for students pursuing advanced manufacturing careers. A series of small investment initiatives was also offered to help "seed" some of these activities with university partnerships.

The complete set of team recommendations can be found on the workshop website [12].

\section{CLOSING REMARKS \& RECOMMENDATIONS}

\subsection{Summary of Workshop Outcomes}

As outlined in Figure 1, the engineering design process provided an organizing framework for the workshop and its execution. The objective of the first working group session was to establish customer requirements by answering the question, "What should we teach the AM workforce and why?" From the working groups, five key themes emerged: (1) AM processes and process/material relationships, (2) engineering fundamentals with an emphasis on materials science and manufacturing, (3) professional skills for problem solving and critical thinking, (4) design practices and tools that leverage the design freedom enabled by AM, and (5) crossfunctional teaming and ideation techniques to nurture creativity.

Following presentations on existing examples of AM education and national manufacturing educational initiatives, the participants worked together to answer the questions, "To whom, where, and how should we teach AM?," and "How should we partner?" The six presented concepts included (1) a lifelong "AM training pyramid" spanning K-12 through R\&D that 
combines AM skill and knowledge acquisition with AM incubators and design competitions to grow and nurture AM communities; (2) a national network for AM education that leverages and expands NSF's successful ATE programs; (3) a MAKE-brary initiative that seeks to create maker spaces in every community, (4) open source educational resources for AM; (4) after-hours AM training programs for incumbent workers and awareness programs for their families; (5) AM courses and curricula for K-5, middle school, high school, community colleges, and universities with cross-linkages across all levels; and (6) a series of small grant initiatives for initiating new AM educational partnerships, "Engineering Experiences for Undergraduates" programs, and student exchanges.

\subsection{Recommendations for AM Education \& Training}

Based on the invited presentations and small group discussions at the workshop, we offer the following recommendations to enhance the AM workforce. Specific actions for academia and industry follow each recommendation.

- Ensure that AM curricula provide students with an understanding of (i) AM and traditional manufacturing processes to enable them to effectively select the appropriate process for product realization; (ii) the relationships between AM processes and material properties; and (iii) "Design for AM", including computational tools for AM design as well as frameworks for process selection, costing, and solution generation that take advantage of AM capabilities. Academics will need to develop (and share) new curriculum and courses to meet this need, and companies will need to engage academic partners to ensure that the curriculum is relevant and reflective of the challenges they are facing in the real world when adopting and using AM. 
- Establishment of a national network for AM education that, by leveraging existing “distributed" educational models and NSF's ATE Programs, provides open source resources as well as packaged activities, courses, and curricula for all educational levels (K-Gray). Academics will need to help populate, curate, and disseminate information in this national AM network, and companies will need to be engaged to define a robust set of "customer needs" for this network (e.g., who will access, how will they access it, where will they access it, what is hands-on versus online) while helping sustain the effort and keep it relevant as AM technology evolves.

- Support K-12 educational programs in STEAM (STEM plus the arts) and across all formal and informal learning environments in order to leverage the unique capabilities of AM while engaging students in hands-on, tactile, and visual learning activities to prepare them for jobs in industry while learning how to think differently when designing for AM. Academics and industry participants can work together to develop these programs and excite future generations of students in the STEAM disciplines to consider careers in AM. For academics, K-12 educational activities provide a means to generate broader impact for their AM research. In industry, many companies already engage in outreach programs and K-12 activities with local schools, and this is a great way to learn how younger students think differently when it comes to $A M$ and $3 D$ printing. This is probably one of the biggest challenges that we heard and have seen from established companies - how do we get our designers and engineers to think (and design) differently when it comes to AM? Getting involved with K-12 programs in STEAM that leverage 3D printing to excite future designers, engineers, and "makers" in AM provides a means for companies to gain insight new ways of utilizing AM technology beyond traditional manufacturing means. 
- Provide support for collaborative and community-oriented maker spaces that promote awareness of AM among the public and provide AM training programs for incumbent workers and students seeking alternative pathways to gain AM knowledge and experience. Academics, and certainly students, can help staff, develop, and run programs in these maker spaces, and companies can provide resources (e.g., money, equipment) to help staff and equip these maker spaces while leveraging their programs to retrain their workforce. By collaborating on such maker spaces, academics will gain insight into the real challenges facing companies with not only applying AM but also training their workforce to use AM. Meanwhile, companies can create new career pathways for their employees while identifying AM expertise within the community and academia that may improve their own operations.

A vision for "layering" these national, regional, and local efforts for AM education and training as shown in Figure 18. This layered approach is based on an analogy to NSF's I-Corps vision to create a national "fabric" to foster innovation and promote research commercialization [18]. The NSF I-Corps program offers support for individual teams to commercialize their research and connect with mentors from across the country. Regional I-Corps sites are being established to enable local teams and provide additional resources and support, and a national network of I-Corps nodes offer immersion curriculum and engage in research about commercialization. 


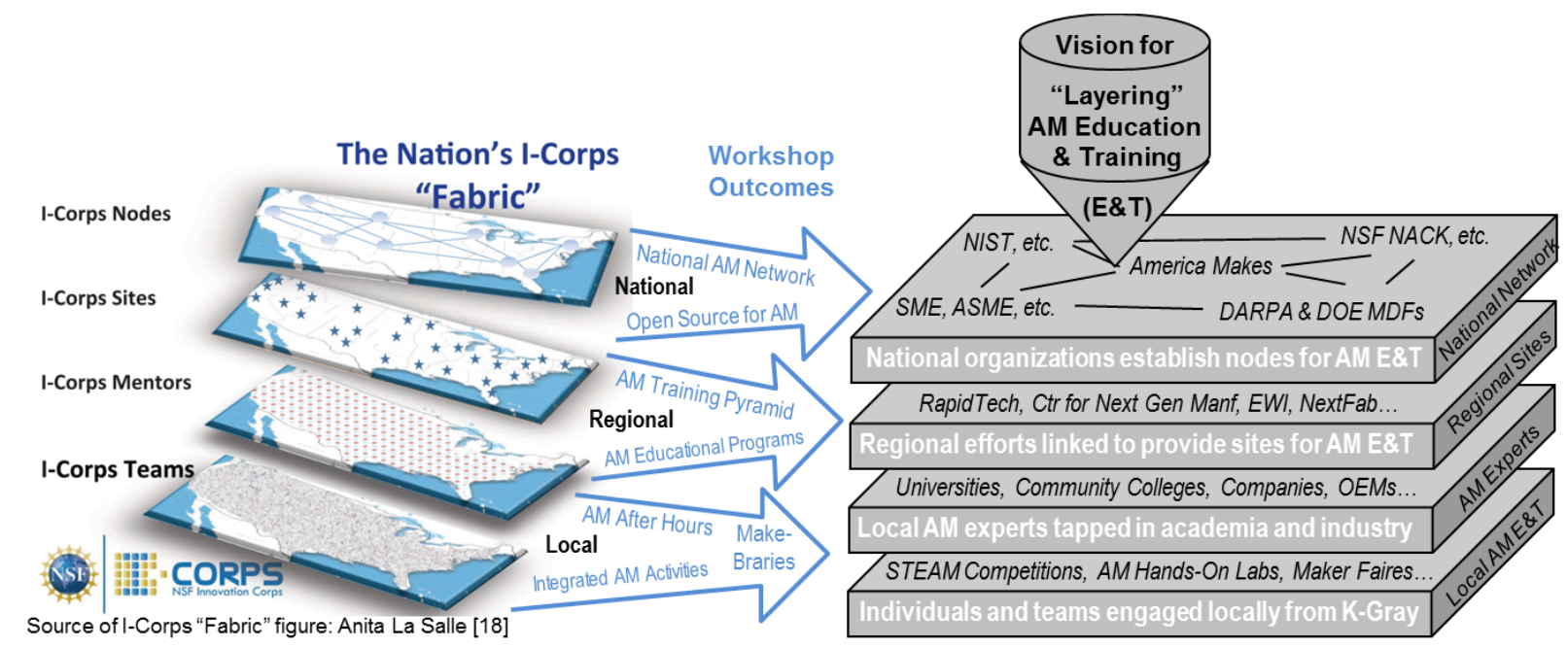

Figure 18. A Vision for "Layering" AM E\&T Based on Analogy to NSF I-Corps Programs

Analogous to these NSF I-Corps programs, many organizations at the workshop (and many not in attendance) are already engaging in multiple efforts that support multiple "layers" of this AM E\&T vision. The challenge lies in connecting them into a coherent network to create synergies that address the pressing and growing need for AM E\&T, and the team suggestions discussed in Section 4 provide a means for cross-linking these efforts across multiple layers as shown in the figure. Specifically, the workshop outcomes from the teams are grouped by their use at the national, regional, and local levels to establish a national AM network that links regional sites for AM E\&T, which tap into local AM experts in industry and academia that engage individuals and teams locally in integrated AM E\&T activities from K-Gray.

Additive manufacturing requires a truly integrated and interdisciplinary approach, and the quicker we can get everyone working together on this exciting technology, the more exciting the advancements and outcomes will be. We believe that the proposed vision for "layering" AM E\&T provides the cross-linkages and collaborations that are needed to not only advance AM technology but also prepare the current and future workforce to harness AM's potential. 


\section{ACKNOWLEDGMENTS}

The authors express their gratitude for the members of the workshop steering committee for their help in shaping the agenda and soliciting speakers and participants: Katie Feldman (NSF), Paul Witherell (NIST), Raj Manchanda (ASME), Ed Tackett (RapidTech), Perry Morrisette (Boeing), Jesse Roitenberg (Statasys), Shawn Kelly (EWI), David Rosen (Georgia Tech), Richard A. Wysk (NC State), and Carolyn Conner-Seepersad (University of Texas - Austin). The authors acknowledge support from NSF Grants CMMI-1431566 and CMMI-1431785. Any opinions, findings, and conclusions or recommendations expressed in this paper are those of the authors and do not necessarily reflect the views of the National Science Foundation.

\section{REFERENCES}

1. Bourell, D. L., Leu, M. C. and Rosen, D. R., Eds., 2009, Roadmap for Additive Manufacturing: Identifying the Future of Freeform Processing, The University of Texas at Austin, Austin, TX, http://amcrc.com.au/wp-content/uploads/2013/03/ADDITIVEMANUFACTURING-2009-Roadmap.pdf

2. Bourell, D. L., Beaman, J. J., Jr., Leu, M. C. and Rosen, D. W., 2009, "A Brief History of Additive Manufacturing and the 2009 Roadmap for Additive Manufacturing: Looking Back and Looking Ahead", RapidTech 2009: US-Turkey Workshop on Rapid Technologies, Istanbul Technical University, http://iweb.tntech.edu/rrpl/rapidtech2009/bourell.pdf

3. Bourell, D. L., Rosen, D. W., Leu, M. C., 2014, "The Roadmap for Additive Manufacturing and its Impact," 3D Printing and Additive Manufacturing, 1(1): 6-9.

4. Bohn, J. H., 1997, "Integrating Rapid Prototyping into the Engineering Curriculum - A Case Study," Rapid Prototyping Journal, 3(1), 32-37. 
5. Williams, C. B. and Seepersad, C. C., 2012, "Design for Additive Manufacturing Curriculum: A Problem- and Project-Based Approach", International Solid Freeform Fabrication Symposium, Austin, TX.

6. Gibson, I., Rosen, D. W. and Stucker, B., 2010, Additive Manufacturing Technologies: Rapid Prototyping to Direct Digital Manufacturing, Springer, New York, NY.

7. Lipson, H. and Kurman, M., 2013, Fabricated: The New World of 3D Printing, Wiley, New York.

8. Huang, Y. and Leu, M. C., 2014, Additive Manufacturing Research and Education: An NSF Additive Manufacturing Workshop Report, July 11-12, 2013. http://nsfam.mae.ufl.edu/2013NSFAMWorkshopReport.pdf

9. The Advanced Manufacturing and Logistics Symposium, October 17-18, 2013, Raleigh, NC., http://camal.ncsu.edu/research/ise-symposium-presentations/

10. Workshop on Future Research Needs in Advanced Manufacturing from Industrial Perspective, August 12-13, 2013, Arlington, VA.

\section{http://advancedmanufacturing2013.northwestern.edu/}

11. Simpson, T. and Williams, C., 2014, "Educational Needs and Opportunities in Additive Manufacturing: Summary and Recommendations from a NSF Workshop,”

\section{http://www.enge.vt.edu/nsfamed/}

12. Williams, C. and Simpson, T.W., 2014, National Science Foundation Workshop on Additive Manufacturing Education Website, April 10-11, http://www.enge.vt.edu/nsfamed/

13. Caffrey, T. and Wohlers, T., 2014, "3D Printing Builds Up Its Manufacturing Resume," Manufacturing Engineering, June, 61-68. 
14. Williams, C. B. and Seepersad, C. C., 2012, "Design for Additive Manufacturing Curriculum: A Problem and Project-Based Approach", International Solid Freeform Fabrication Symposium, Austin, TX, p. 81-92.

15. Virginia Tech DreamVendor 3D Printing Vending Machine, 2012, http://www.dreams.me.vt.edu/dreamvendor

16. Virginia Tech Additive Manufacturing Design Competition, 2014, http://vt-arcdc.org/

17. Williams, C.B., 2015, “Advancing Student Learning of Design for Additive Manufacturing Principles through an Extracurricular Vehicle Design Competition,” ASME IDETC Design Education Conference, Boston, MA (under review)

18. La Salle, A. J., 2012, "I-Corps: NSF Innovation Corps", University Innovation Summit, The Virginia Tech Research Center, Arlington, VA, NCIIA, November 8, 2012. 